\title{
Cost-Sharing as a Financing Mechanism in the Greek Primary Health Care: An Assessment from the Managers' Perspective
}

\author{
Eleni G. Stokou', Athanassios Vozikis ${ }^{2, *}$, Gregory P. Chondrocoukis ${ }^{3}$ \\ ${ }^{1}$ Nursing Department, Athens University, Athens, Greece \\ ${ }^{2}$ Economics Department, University of Piraeus, Piraeus, Greece \\ ${ }^{3}$ Department of Industrial Management, University of Piraeus, Piraeus, Greece \\ *Corresponding author: avozik@unipi.gr
}

Received December 30, 2012; Revised February 05, 2013; Accepted February 25, 2013

\begin{abstract}
Cost-sharing was recently introduced in the Greek Primary Health Care, as a supplementary mechanis $m$ to finance spiraling health expenditure and to make patients cost-conscious.

A specific questionnaire was distributed to the 188 managers of the health centres in Greece (response rate 93 per cent). The research was conducted from June 2011 to May 2012. Statistical analysis was performed using the Pears on $x^{2}$ test, the Kolmogorov-Smirnov test, the $t$-test and the Mann-Whitney test at $p<0.05$ level of significance. 73 per cent of the managers stated that the introduction of the cost-sharing had a positive impact on patients' compliance and 66.3 per cent that the financing mechanism has contributed to cost consciousness from both the patients and personnel. The revenues from medical fees do not cover the running costs of health centres (81.5 per cent) and they do not promote a more effective delivery of services ( 80 per cent). 61 per cent of managers characterise cost-sharing as a positive step and 80 per cent support the economic autonomy of health centres.

Managers stated that cost-sharing has a positive impact on patients' cost-consciousness and in the financing of the primary health care in Greece, but this policy option alone doesn't assure the financial and adminis trative viability of the health centres.
\end{abstract}

Keywords: Greek primary health care, health centres, cost-sharing, health care financing, managers

\section{Introduction}

Improved medical care and increasing number of elderly population have resulted in spiraling health expenditure all over the world [1]. In order to address this problem, several countries have implemented various policies of patient contribution in the financing of health services [2,3]. It has been argued that these policies may lead to the reduction of excessive demand and moral hazard, by strengthening the relationship between service and payment, resulting to the improvement of societal welfare as well as improved quality and availability of health services [4-9].

However, cost-sharing is a matter of controversy because of its adverse effects regarding to the access to medical services and prescription drugs, to the level of the health status and to the efficiency and equity in providing health services. As far as equity in the use of health care is concerned to negatively affected by cost-sharing, because low-income population have to pay a greater proportion of their revenues than the high-income $[10,11,12]$, exceptions are provided for certain vulnerable social groups, a fact that renders the implementation and management of cost-sharing mechanisms more complex and costly [13]. As a result, cost-sharing may cause small gains but its implementation as a tool to increase costconsciousness not only from patients' but also from providers' side is considerable [12,14].

On the other hand, in the case of abolition of costsharing in the units where is already applied, this will result in the deteriorating of quality and the excessively increasing of demand [15]. Moreover, accord ing to a study contacted in Germany the respondents consider that to patients with hazard addictions such as smoking, or with dangerous life style behavior such as extreme sports, increased financial contribution must be implemented [16].

According to Wranik Dominika, life expectancy as a health outcome is 1.01 years higher in countries where cost-sharing is required and efficiency of health expenditures is higher in health systems where insurance coverage is wide-spread and patients share a certain amount of the medical treatment cost [17]. This positive effect outweighs the drawback of financial burden for some groups of population. However, if patients are not adequately informed they may avoid necessary health treatment deteriorating their health and that will result in increased costs, in growth in the use of acute services, undermining the efficiency of the health care system. Medical fees should be set in a reasonable amount to keep accessible health services to all social strata in order to 
avoid resultant costs from the reduction of the use of essential medical utilisation and augmentation of morbidity [10]. Moreover, existing informal payments have to be minimised and a public discussion should form the content, the extent and the objectives of cost-sharing $[3,6]$.

\section{The Greek health care system}

In Greece, according to OECD data, health expenditure has risen from 5.9 per cent of the GDP in 1980 to 6.7 per cent in 1990 to 8.0 per cent in 2000 to 10.2 per cent in 2010. Meanwhile, the percentage of state funding of health expenditure has been 55.6 per cent in $1980,53.7$ per cent in 1990, 60.0 per cent in 2000 and 59.4 per cent in 2010 [18]. Private health costs as a percentage of the total health expenditures were 40.6 per cent in 2010 [19].

It is paradoxical that although the Greek Health Care System is public, Greece is among the countries with the highest private health expenditures in the European Union. 66 per cent of the total private health expenditures are for outpatient health visits and citizens in rural areas are more often visiting private health units than in urban areas [20]. Consequently, cost-sharing in primary health care would probably increase the resources allocated to public health services covering the shortcomings of rural health centres and reducing visits to privately offered medical care.

Until 2010, in Greece health centres covered their expenses exclusively from the state budget. However, in order to limit the moral hazard phenomenon, in September 2010 the Health Ministry announced that a patient's contribution in the cost for outpatient services would be three euros for each medical visit (Circular of Greek Health Ministry, 2010) which in January 2011 it amounted to five euros (Circular of Greek Health Ministry, 2011). With regard to laboratory tests patients pay the amount defined in the applicable circular "On the regulation of payments for medical visits and acts" (Circular of Greek Health Min is try, 2010).

The scope of our research is to assess the introduction and the initial results of the novel cost-sharing mechanism, from the managers' aspect. Its novelty lies in that is the first attempt to assess this cost-sharing mechanism in the Greek primary health care, not from the users' (patients') point of view, but from an administrative pers pective, vital in the success of this policy option.

\section{Materials and Methods}

The data of our research were collected through a specific questionnaire, distributed at all health centres in Greece (in total 202 health centers) except from mental health centres, to be answered by the managers of these units. The questionnaire was developed identifying the domains and items of relevance. Health economists and health professionals were involved in the identification of core dimensions and in the creation and the selection of the items to be included in the questionnaire.

The control of content valid ity of the questionnaire was accomplished through a pilot research $(n=25)$. Out of the total of 202, 188 health centres' managers consented to participate and answered the questionnaire (93 per cent response rate). The research was conducted from June 2011 to May 2012. The collection of the answers was achieved mainly by telephone communication and consecutively by fax exchange (in case the managers were not available to provide the answers by phone). In some cases the personal contact was considered necessary. Besides the answers to the structured questionnaire, additional opinions revealed from the contact with the managers, which were taken into consideration in the results and discussion section.

The questionnaire consists of thirteen questions (eleven with fixed response and two open ended. The questionnaire is structured in two main parts: a) the impact of cost-sharing mechanism regarding the provision of services in health centres and the personal views of the managers regarding the funding of these units, and b) various demographic and other characteristics of managers.

We input the data to and perform their analysis using the IBM SPSS Statistics 19 software. We used the Pearson $\mathrm{x}^{2}$ test in order to test the independence between two categorical variables. To check the significance of difference between the mean values of continuous variables we used the Student t-test or the Mann-Whitney test, after the Kolmogorov-Smirnov test which checks for the normality of the distribution of these variables. In all statistical analyses we used the $\mathrm{p}<0.05$ level of significance. Continuous variables are presented as mean values, while categorical variables are presented as relative frequencies.

\section{Results}

\subsection{Demographic and other Characteristics of the Sample}

Various characteristics of the managers' sample are presented in Table 1. It is observed that 71 per cent of the respondents were men $(n=134)$ and the mean age was 56 years $($ median $=57$, range $=35-67)$. The mean years of service was 19 (median=22, range $=1-34)$. Also, 93 per cent $(n=174)$ of the managers were graduates of medical school and 28 per cent $(n=51)$ had post graduate degrees. Only 7 per cent $(n=13)$ of the managers hold a master's degree related to in health services management, so incentives should be given to managers to undertake postgraduate studies in the health services administration for better planning of health centres. Finally, 9 per cent $(n=16)$ of managers hold a PhD title (Table 1).

Table 1. Various characteristics of Managers

\begin{tabular}{|c|c|c|c|}
\hline Variable & \multicolumn{3}{|c|}{ Managers } \\
\hline Gender & \multicolumn{2}{|c|}{ Number (N, \%) } & $\begin{array}{c}\text { Cumulative } \\
\text { Percent }\end{array}$ \\
\hline Male & 134 & $71.3 \%$ & $71.3 \%$ \\
\hline Female & 54 & $28.7 \%$ & $100 \%$ \\
\hline Age (Mean-range) & $56(35-67)$ & & \\
\hline Years of service & $19(1-34)$ & & \\
\hline Education & & & \\
\hline Medical school graduates & 174 & $92.6 \%$ & $92.6 \%$ \\
\hline Dental school graduates & 14 & $7.4 \%$ & $100 \%$ \\
\hline Post graduate degree & & & \\
\hline Yes & 51 & $27.7 \%$ & $27.7 \%$ \\
\hline No & 133 & $72.3 \%$ & $100 \%$ \\
\hline MSc in Health Management & & & \\
\hline Yes & 13 & $7.2 \%$ & $7.2 \%$ \\
\hline No & 168 & $92.8 \%$ & $100 \%$ \\
\hline Doctorate & & & \\
\hline Yes & 16 & $8.9 \%$ & $8.9 \%$ \\
\hline No & 164 & $91.1 \%$ & $100 \%$ \\
\hline
\end{tabular}




\subsection{Aspects of Managers Regarding Financing Mechanism in Primary Health Care}

Regarding the introduction of the cost-sharing mechanis $m$ in health centres 61 per cent of managers characterised it as a positive experience so far and 73 per cent said that patients comply with the payment of fees. In relation to the reaction of the employees towards the introduction of the financing mechanis $\mathrm{m}$, the percentage of the managers who responded that employees comply is 56 per cent. To the question of whether the revenues from medical fees are adequate and if they cover the costs of health centres 81.5 per cent responded negatively. Many of the respondents in the personal communication justified their answer by stating that the revenues from fees were passed to the affiliated hospital and therefore were not directly used to address health centres' needs. For the above reason, a large proportion of respondents (80 per cent) said that the financing mechanism does not contribute to a more effective services provision by health centres.

Moreover, 66.3 per cent of managers responded that the cost-sharing mechanis $m$ has contributed to cost consciousness from both the patients and personnel. Patients tend to use less medical services when they pay out of pocket than in the case of social insurance [5] and personnel is more aware in the use of medical equip ment.

When managers were asked whether they agree with the economic autonomy of health centres regarding the ability to manage their own revenues, 80 per cent responded positively. Moreover, on the issue of whether the revenues from the financing mechanism could contribute to the efficient operation of health centres, given their administrative independence, 80 per cent responded in the affirmative. All the managers who have a master's degree in organisation and administration of health centres responded positively in this question (marg inal statis tically significant $\mathrm{x}^{2}=3.5, \mathrm{p}=0.06$ ).

The managers who answered positively to the question about the contribution of the financing mechanism to the efficient operation of health centres were asked to specify the reasons why they consider that the collection of fees will contribute to a more effective operation of the health centres. As Table 2 illustrates, 99 per cent of the managers mentioned that the financing mechanis $m$ will solve the health centres financial flow problems, 82 per cent that it will result in the development of preventive and health promotion programmes and 73 per cent that it will contribute to the enrich ment and upgrading of the existing medical equipment of the centres. Only 38 per cent of the respondents said that the financing mechanism will make the employ ment of assisting personnel possible.

On the other hand, 75 per cent of the managers who answered that the collection of medical fees will not contribute to the efficient operation of health centres in the case of autonomy, believe that cost-sharing is unfair and 68 per cent that the administrative dependence of health centres on hospitals contributes to the efficient operation.

\subsection{Results from Correlation Analysis}

Combining the managers' answers some conclusions are derived as Table 3 depicts. Firstly, 90 per cent of the managers who consider the introduction of the costsharing mechanism as positive reported that patients comply with the payment of fees. By contrast, only 46 per cent of the respondents who consider the introduction of the financing mechanism as negative, reported that patients comply $\left(\chi^{2}=45, \mathrm{p}=0.001\right)$.

Table 2. Positive and negative attitude to the question if the financing mechanism could con tribute to the efficient ope ration of heal th centres

\begin{tabular}{|c|c|c|c|c|}
\hline Answers & \multicolumn{2}{|c|}{ Yes } & \multicolumn{2}{|c|}{ No } \\
\hline POSITIVE & \multicolumn{2}{|c|}{$\begin{array}{c}\text { Number } \\
(\mathrm{N}, \%)\end{array}$} & \multicolumn{2}{|c|}{$\begin{array}{c}\text { Number } \\
(\mathrm{N}, \%)\end{array}$} \\
\hline $\begin{array}{c}\text { It will solve the health centres } \\
\text { liquidity problems }\end{array}$ & 149 & $99 \%$ & 2 & $1 \%$ \\
\hline $\begin{array}{c}\text { It will make the employment of } \\
\text { assist ing personnel possible }\end{array}$ & 57 & $38 \%$ & 94 & $62 \%$ \\
\hline $\begin{array}{c}\text { It will contribute to the enrichment } \\
\text { and upgrading of the existing } \\
\text { medical equipment of the centres }\end{array}$ & 109 & $73 \%$ & 41 & $27 \%$ \\
\hline $\begin{array}{c}\text { It will result in the development of } \\
\text { preventive and health promotion } \\
\text { programmes }\end{array}$ & 122 & $82 \%$ & 27 & $18 \%$ \\
\hline $\begin{array}{c}\text { NEGAT IVE } \\
\text { Nume dependence of health centres } \\
\text { on hospitals contribut es to the } \\
\text { efficient operat ion }\end{array}$ & 19 & $68 \%$ & 9 & $32 \%$ \\
\hline Cost-sharing is unfair & 21 & $75 \%$ & 7 & $25 \%$ \\
\hline
\end{tabular}

Note: 151 from $188(80 \%)$ are the managers who respond that the income from the financing mechanism could contribute to the efficient operation of health centres, given their administrative independence and 37 from $188(20 \%)$ respond negatively

Furthermore, 72 per cent of those managers who consider the function of the financing mechanis $m$ as positive indicated that administrators do not react against the additional tasks assigned to them, but 33 per cent of the managers who consider the function of the financing mechanis $m$ as negative indicated that administrators comply $\left(\chi^{2}=26.5, p=0.001\right)$. From the managers that characterised the function of the financing mechanism as positive 74 per cent said that the revenues from fees are inadequate and cannot cover a health centre's costs and 93 per cent of the managers who have characterised the function of the financing mechanis $m$ as negative noted that the revenues from fees are inadequate and do not cover the expenses of a health centre $\left(\chi^{2}=11, p=0.001\right)$.

From the respondents who reported that the function of the financing mechanis $m$ is positive 69 per cent believe that it does not contribute to effective delivery of services by health centres. Investigating the percentage of managers who consider that the function of the financing mechanis $\mathrm{m}$ is negative it is observed that 97 per cent of them reported that revenues have not contributed to the effective delivery of services by health centres $\left(\chi^{2}=22\right.$, $\mathrm{p}=0.001$ ).

From the managers who said that the financing mechanis $\mathrm{m}$ is functioning positively 84 per cent stated that it contributes to cost consciousness of patients and personnel, but 38 per cent of the managers who stated that the financing mechanis $\mathrm{m}$ is functioning negatively mentioned that it contributes to cost consciousness of patients and personnel $\left(\chi^{2}=42, p=0.001\right)$. Moreover, 88 per cent of the managers who stated that the financing mechanis $\mathrm{m}$ is functioning positively believe that if there is administrative independence in the management of the collected medical fees there will be improvement in the efficiency of health care services and 69 per cent of the 
managers who stated that the financing mechanis $m$ is functioning negatively reported that in the case of administrative independence there will be improvement in the efficiency of their services $\left(\chi^{2}=10, p=0.002\right)$.

Table 3. Correlation be tween manage rs' an swe rs

\begin{tabular}{|c|c|c|c|c|c|}
\hline \multicolumn{2}{|l|}{ Variables } & \multicolumn{4}{|c|}{ Operation of financing mechanism } \\
\hline & & & $\%)$ & & \%) \\
\hline \multirow{3}{*}{ Patients' compliance } & Yes $(\mathrm{N}, \%)$ & 103 & $90 \%$ & 34 & $46 \%$ \\
\hline & No $(\mathrm{N}, \%)$ & 11 & $10 \%$ & 40 & $54 \%$ \\
\hline & Total $(\mathrm{N}, \%)$ & 114 & $100 \%$ & 74 & $100 \%$ \\
\hline \multirow{3}{*}{ Administrators' att itude } & Positive $(\mathrm{N}, \%)$ & 78 & $72 \%$ & 24 & $33 \%$ \\
\hline & Negative $(\mathrm{N}, \%)$ & 31 & $28 \%$ & 49 & $67 \%$ \\
\hline & Total $(\mathrm{N}, \%)$ & 109 & $100 \%$ & 73 & $100 \%$ \\
\hline \multirow{3}{*}{ Adequacy of revenues } & Yes $(\mathrm{N}, \%)$ & 29 & $26 \%$ & 5 & $7 \%$ \\
\hline & No $(\mathrm{N}, \%)$ & 82 & $74 \%$ & 68 & $93 \%$ \\
\hline & Total $(\mathrm{N}, \%)$ & 111 & $100 \%$ & 73 & $100 \%$ \\
\hline \multirow{3}{*}{$\begin{array}{l}\text { Contribution of medical fees in efficiency of health } \\
\text { centres }\end{array}$} & Yes $(\mathrm{N}, \%)$ & 35 & $31 \%$ & 2 & $3 \%$ \\
\hline & No $(\mathrm{N}, \%)$ & 79 & $69 \%$ & 72 & $97 \%$ \\
\hline & Total $(\mathrm{N}, \%)$ & 114 & $100 \%$ & 74 & $100 \%$ \\
\hline \multirow{3}{*}{$\begin{array}{l}\text { Contribution of medical fees to cost consciousness of } \\
\text { patients and personnel }\end{array}$} & Yes $(\mathrm{N}, \%)$ & 96 & $84 \%$ & 28 & $38 \%$ \\
\hline & No $(\mathrm{N}, \%)$ & 18 & $16 \%$ & 45 & $62 \%$ \\
\hline & Total $(\mathrm{N}, \%)$ & 114 & $100 \%$ & 73 & $100 \%$ \\
\hline \multirow{3}{*}{$\begin{array}{l}\text { Contribution of medical fees to the efficiency of } \\
\text { services in the case of administrative independence }\end{array}$} & Positive (N, \%) & 100 & $88 \%$ & 51 & $69 \%$ \\
\hline & Negative (N, \%) & 14 & $12 \%$ & 23 & $31 \%$ \\
\hline & Total $(\mathrm{N}, \%)$ & 114 & $100 \%$ & 74 & $100 \%$ \\
\hline
\end{tabular}

From the managers who agree with the financial autonomy of health centres, 91 per cent consider that collecting medical fees will allow for a more efficient operation of health centres if they have administrating independence. On the other hand, 65 per cent of the managers who do not agree to the financial autonomy of health centres, considers that revenues from the financing mechanis $m$ will not lead to a more efficient provision of health services if health centres are self administered $\left(\chi^{2}=59.5, p=0.001\right)$.

Concluding this section we observe that managers' opinion concerning the function of cost-sharing mechanis $m$ is related with the attitude of the patients and administrators and with the benefit of cost consciousness. In addition, all the managers regardless of their confirmation or not towards financing mechanism pointed that revenues do not contribute to the costs and the effectiveness of health centre. However, in a condition of economic autonomy these revenues could contribute to the effective operation of health centres.

\section{Discussion and Conclusions}

The demand for healthcare services is highly affected by cost-sharing, as it can not only decrease unnecessary use, but it can also encourage the use of preventive care if it is free of charge or at a low level of user charge. Copayments and private health insurance prevent people from an unhealthy lifestyle [21].

According to Kentikelen is et al. (2011) in 2009, when financial crisis occurred in Greece, more people -than in 2007- reported that they avoided to visit a doctor despite the necessity and that health outcomes have worsened, especially in vulnerable groups [22]. Moreover, a research by the National School of Public Health in Greece reported that in 2011 health expenditures have been decreased 36 per cent [23]. According to Health Ministry's report of annual results the visits in health centres increased $22 \%$ in 2011 than 2010 , and $4 \%$ in 2010 than 2009. This in connection with the increase of $30 \%$ in hospital visits in 2011 and $11 \%$ in 2012, according to estimation of Health Ministry, results to the conclusion that cost-sharing did not deter citizens from visiting health units [24,25].

In a research conducted in Greece in 2008 (Stokou, E., 'Health Centres in Greece and the introduction of $a$ financing mechanism in them', University of Piraeus, unpublished data) before the introduction of cost-sharing in health centres, which calculates the potential revenues from its implementation, it was observed that revenues in urban health centres and non-urban ones in tourist areas exceed the cost required for the establishment and maintenance of the financing mechanis $\mathrm{m}$. However, in the same survey it was found that this does not apply to rural areas, where patients insured by the Farmers Insurance Agency (OGA) and are exempted from paying medical fees, outnumber the other patients. However, revenue growth at the other health centres may lead to savings from the budget of the Ministry of Health which will be used to cover the deficits of rural health centres .

Analyzing the views of the managers is entailed that although cost-sharing contributed to the cost consciousness of patients and personnel and increase the revenues of the National Health System, the revenues are passed to the affiliated hospitals and fail to meet the cash flows requirements of the health centres and they cannot be used towards improving the provided services. Only in the case of economic autonomy of health centres the improvement of their services will be possible through recruiting as sistant doctors who would cover the vacancies, purchasing certain medical equipment, renovating the buildings which house the Centres [26] and developing prevention and health promotion programmes.

In Vietnam health providers cause increase in the demand for health services in which user charges are imposed to counterbalance the constraint of public resources. As a result cost-sharing was associated with increases in the intensity of health care [27].

As far as policy planning is concerned adherence of preventive care and prevalence of a healthier lifestyle is the most effective way to cost savings [21]. Cost-sharing mechanis m must be consistently applied and designed in a way that is not conflicted with other policy goals, in order to be profitable for the health system not only in short term but also long lasting [10]. 
Another suggestion to improve cost savings without deteriorating health outcomes is the "benefit-based copays" depending on scientific evidence designing the price of cost-sharing [28]. Also a matter of concern is the type of services that will be forgone, namely whether policy makers will choose those which enhance or stabilizing health, or alternatively, those of little value [6].

Another issue is the exemption policies which will be imposed not only to protect low-income and older groups but also concentrating on different needs of different groups of population increasing equity, without worsening administrative efficiency [10]. The contribution of middle and high income citizens is necessary in this day and age in order to enable the continuity of the welfare state because the country is experiencing economic recession and the availability of public subsidy to health care and the poor is low.

Moreover, the Switzerland model, that introduces, besides demand side cost-sharing the supply side costsharing in order to mitigate the moral hazard effect, might be of interest [29]. As far as the use of medical services is increased by patients the amount of insurance deductible will be increased.

Some limitations of our research can be focused on the hesitation of some managers to answer the questionnaire, as well as the limited time between the introduction of the regulation and the conduction of our study, which might not considered sufficient to fully depict the benefits from cost-sharing in the health services provision.

In conclusion, health centres should be considered and encountered as important contributors to the primary health care and be part of the general strategic planning of it. Specifically, health centres should be strengthened through:

- Employ ment of general practitioners (GPs)

- Develop ment of infrastructure

- Development of information systems and

- Staffing with human resources

Moreover, the implementation of cost-sharing needs firstly the acute calculation of the costs of all services provided in the health centres. In addition, the question of operational affiliation or autonomy of primary health centres' services have to be answered after cost benefit analysis [30].

The above statements should be considered in connection with the operation of the united insurance fund (EOPYY). The classical methodology of cost control through minimizing the de mand has not positive effects in health and economic terms. Instead, creates development burdens and limits the consumers' rights. On the other hand, cost-sharing between health insurance and consumers on the basis of social efficiency and medical effectiveness will contribute to resource allocation in an optimum way, it will give growth motivation in health sector and it will give to consumers the right of choice. In this sense insurance policy have to provide effective medical treatment and its reimbursement will be proportionally allocated between insurance funds and citizens, with criteria of social efficiency and medical effectiveness [25,31,32,33].

Additional research is necessary to adequately address the issue, regarding cost- benefit analysis, the views of the clinical and administrative personnel, as well as the users of health services, the long term effects of the financing mechanis $m$ on improving the services of health centres and the reduction of private expenses as well as the improvement of the population's health.

\section{Acknowledgments}

We thank all the managers of the health centres who participated in this study. We also want to thank Evagelia Asimeniou for her language contribution in the article and the reviewers for their comments.
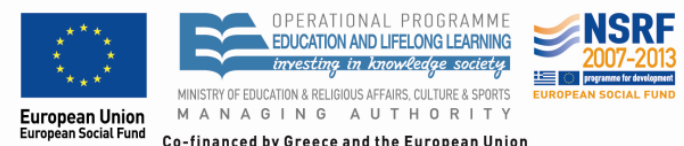

This research has been co-financed by the European Union (European Social Fund - ESF) and Greek national funds through the Operational Program "Education and Lifelong Learning" of the National Strategic Reference Framework (NSRF) - Research Funding Program: Heracleitus II. Investing in knowledge society through the European Social Fund.

\section{Statement of Competing Interests}

The authors have no competing interests

\section{References}

[1] OECD, Statistics: Demography, Old age support ratio, Available: http://www.oecd.org/document/0,3746,en_2649_201185_4646275 9_1_1_1_1,00.html, accessed 20 Sept ember 2012.

[2] O’Reilly, D., O’Neill, C., O’Dowd, T., Galway, K., Gilliland, A., Kelly, A., Murphy, A., Shryane, E., Steele, K., Bury, G., "Patients' attitudes to co-payments for general practitioner services: do they reflect the prevailing system", Joumal of Health Services Research and Policy, 12 (4). 2007.

[3] Tambor M., Pavlova M., Woch P., Groot W., "Diversity and dynamics of patient cost-sharing for physicians' and hospital services in the 27 European Union countries", European Journal of Public Health, Oxford University Press, 21(5). 585-590. 2010.

[4] Bolin, K., Lindgren, A., Lindgren, B., Lundborg B., "Utilization of physician services in the 501 population: the relative importance of individual versus institutional factors in 10 European countries", Intemational Journal of Health Care Finance and Economics, 9 (1). 83-112. 2009.

[5] Wagner, T., Heisler, M., Piette, J., "Prescription drug co-payments and cost-related medication underuse", Health Economics, Policy and Law, 3 (1). 51-67. 2008.

[6] Rice, T., Matsuoka, K.Y., "The impact of cost-sharing on appropriate utilization and health status: a review of the literature on seniors", Medical Care Research and Review, 61 (415). 2004.

[7] Hurst S. A., Danis M., "Indecent Coverage? Protecting the Goals of Health Insurance from the Impact of Co-Payments", Cambridge Quarterly of Healthcare Ethics, Cambridge University Press, 15. 107-113. 2006.

[8] Weale A., Clark S., "Co-payments in the NHS: an analysis of the normative arguments", Health Economics, Policy and Law, Gambridge University Press, 5(2). 225-246. 2010.

[9] Rui S., Changhoon J., "Does user-charge financing reduce expenditure levels for the charge-financed services?", The American Review of Public Administration, SAGE, 42(2). 170-185. 2012.

[10] Gemmill, M. C., Thomson, S., Mossialos, E., "What impact do prescription drug charges have on efficiency and equity? Evidence from high-income countries", International Journal for Equity in Health, 7 (12). 2008. 
[11] Robinson, R, User charges for health care, in E. Mossialos, A. Dixon, J. Figueras, J. Kutzin (Eds), Funding health care: options for Europe, European Observatory on Health Care System Series, Buckingham-Philadelphia, 161-183, 2002.

[12] Hassell K., Atella V., Schafheutle E., Weiss M., Noyce P., "Cost to the patient or cost to the healthcare system? Which one matters the most for GP prescribing decisions? A UK-Italy comparison.", European Journal of Public Health, 13. 18-23. 2003.

[13] Mossialos, E., Le Grand, J., Health Care and Cost Containment in the European Union, Ashgate Publishing Limited, Aldershot, 1999.

[14] Reichmann, G., Sommersguter-Reichmann, M., "Co-payments in the Austrian social health insurance system. Analysing patient behavior and patients' views on the effects of co-payments", Health Policy, 67. 75-91. 2004.

[15] McPake B., Brikci N., Cometto G., Schmidt A., Araujo E., "Removing user fees: learning from international experience to support the process", Health Policy and Planning, Oxford University Press, 26. 104-117. 2011.

[16] Rostermundt A., Westphal R., Raspe H., "Relevance and financing of health services: a survey of physicians, students, patients, nursing personnel and seniors", Gesundheitswesen, 63(5). 311-318. 2001

[17] Wranik, D., "Healthcare policy tools as determinants of health system efficiency: evidence from the OECD", Health Economics, Policy and Law, 7. 197-226. 2012.

[18] OECD-Eurostat-WHO Health Accounts (SHA) Data Collection (JHAQ) and OECD Health Data questionnaire, Health Expenditure and Financing. Available: http://stat s.oecd.org/Index.aspx?DataSetCode=SHA\#, accessed 4 September 2012.

[19] WHO Statistics - Health Financing: Health Expenditure Ratios Private expenditure on health as a percentage of total expenditure on health. Available:

http://apps. who.int $/$ minerva/minerva.jsp?theme=main\& vid=1901 D, accessed 18 September 2012.

[20] Siskou, O., Kaitelidou, D., Papakonstantinou, V., Liaropoulos, L., "Private health expenditure in the Greek health care system: Where truth ends and the myth begins", Health Policy, 88. 282293. 2008.

[21] Rezayatmand, R., Pavlova, M., Groot, W., "The impact of out of pocket payments on prevention and health related lifestyle: a systematic literature review", The European Journal of Public Health Advance, 2012.

[22] Kentikelenis, A., Karanikolos, M., Papanicolas, I., Basu, S., McKee, M., Stuckler, D., "Health effects of financial crisis: omens of a Greek tragedy", Lancet, 378. 1457-1458. 2011.

[23] Kentikelenis, A., Karanikolos, M., Papanicolas, I., Basu, S. McKee, M., Stuckler, D., "Health and the financial crisis in Greece", Lancet, 379. 1002. 2012.

[24] Greek Health Ministry, Report analysis of Health Ministry and NHS units of 2011 http://www.yyka.gov.gr/articles/hlekt ronikes...e-s.../1332-ethsiaekthesh-2011?, accessed 1 February 2013.

[25] Kyriopoulos J., T siantou V., "The financial crisis and its impact on health and medical care", Archives of Hellenic Medicine, 27 (5) 834-840. 2010

[26] Anagnostopoulou, I., Semertziadi, M., Siskou, O., Kaitelidou, D. T sounias, V., "Investigation of the int ent of patients to participate in the cost in the health centre of Atalant e", Archives of Hellenic Medicine, 28 (6). 777-84. 2011.

[27] Sepehri A., Chernomas R., Akram-Lodhi H., "Penalizing patients and rewarding providers: user charges and health care utilization in Vietnam", Health Policy and Planning, Oxford University Press, 20(2). 90-99. 2005.

[28] Fendrick, A. M., Smith, D. G., Chernew, M., Shah, S. N., "A benefit-based copay for prescription drugs: Patient contribution based on total benefits, not drug acquisition cost", American Journal of Managed Care, 7 (9). 861-867. 2001.

[29] Trottmann, M., Zweifel, P., Beck, K., "Supply-side and demandside cost-sharing in deregulated social health insurance: Which is more effective?', Journal of Health Economics, 31 . 231-242. 2012

[30] Lionis C., Wynn-Jones J., "Establishing academic rural practice: a fut ure and challenging target", Rural and Remote Health 7(727). 2007.

[31] Pauly M., "Market power, Monopsony and Health Insurance Markets", Journal of Health Economics, 7. 111-128. 1988.

[32] Pauly M., "Health Insurance and Market Failure in the Medical Economy", Journal of Economic Literature, 15. 629-675. 1986.

[33] 33) Stuckler D, Basu S, Suhrcke M, Coutts A, McKee M. "The public health effect of economic crisis and alternative policy responses in Europe: An empirical analysis". Lancet, 374. 315-323. 2009 . 